\title{
Estudio de la vulnerabilidad y la resiliencia en la ciudad de Santa Fe, Argentina: El rol de los servicios urbanos en general y del transporte de pasajeros en particular
}

\author{
Study of vulnerability and resilience in the city of Santa \\ Fe, Argentina: The role of urban services in general and \\ urban transport in particular
}

\author{
María Mercedes Cardoso ${ }^{1}$
}

\begin{abstract}
RESUMEN
En la teoría del riesgo, la vulnerabilidad y la resiliencia emergen como categorías centrales. El estudio de la vulnerabilidad, de sus dimensiones, su medición y distribución en el territorio representa un diagnóstico imprescindible. La resiliencia, como capacidad de adaptación y transformación del sistema, es una herramienta para la prognosis que posibilita avanzar hacia sociedades más justas y sostenibles. El diseño y aplicación del índice de vulnerabilidad socio-ambiental para la ciudad de Santa Fe, Argentina, devela que los sectores de alto riesgo configuran un cordón al oeste e islas al norte y al este. En 2010, la población más vulnerable a las inundaciones representa el $22 \%$ del total y el $70 \%$ es vulnerable a todo tipo de amenazas. Este trabajo brinda elementos de análisis para el abordaje de la vulnerabilidad y resiliencia a través de la exploración sobre la accesibilidad a los servicios urbanos, caso del transporte de pasajeros.
\end{abstract}

Palabras claves: Vulnerabilidad socio-ambiental, resiliencia, servicios urbanos básicos, transporte urbano de pasajeros, riesgo.

\begin{abstract}
Within risk theory, vulnerability and resilience emerge as significant categories. The study of vulnerability, its dimensions, its measurement, and its territorial distribution constitutes an indispensable diagnose. Resilience, as a capacity of the system for adapting and transforming itself, is a tool for prognosis which also leads to more fair and sustainable societies. The design and implementation of the socio-environmental vulnerability index in the city of Santa Fe, Argentina, has shown the highest risk sectors are found all along the west side of the city, and in the form of islands throughout the north and east sectors. In 2010,22 \% of the total population had the highest flood vulnerability, and $70 \%$ was vulnerable to all kinds of threats. This research provides elements of analysis for approaching vulnerability and resilience by exploring accessibility to urban services, mainly urban passenger transport.
\end{abstract}

Keywords: Socio-environmental vulnerability, resilience, basic urban services, collective transport, risk.

Doctora en Geografía por la Universidad de Salamanca (España). Investigadora Asistente de CONICET, Argentina. Profesora Adjunta de Planeamiento y Ordenamiento Territorial y Geografía Urbana. Facultad de Humanidades y Ciencias, Universidad Nacional del Litoral. Ciudad Universitaria, km 0 Ruta Nacional № 168 (CP 3000) Santa Fe, Argentina, mercecardoso@hotmail.com; mercecardoso@gmail.com 
En América Latina, así como en otras regiones del mundo en desarrollo, gran parte de la población vive en la pobreza, en condiciones de vida que distan mucho de ser dignas. Este problema estructural, producto de décadas de ineficaces políticas económicas y sociales sitúa a la población en una posición de vulnerabilidad frente a ciertos peligros latentes: nuevas crisis económicas, eventos climáticos adversos, desastres naturales, antrópicos o una combinación de ambos. El desastre, lejos de ser un castigo divino es un producto o resultado de la concreción de un riesgo. La intensidad de los daños a él atribuido dependerá, más que de la severidad del evento desatado, de las condiciones y nivel de preparación de la comunidad local, en ese momento, respecto a ese tipo de crisis (Wilches-Chaux, 1993; Foschiatti, 2009). El resultado estará en función de sus habilidades, fortalezas, debilidades, incapacidades, estrategias de afrontamiento y respuesta.

La vulnerabilidad y la resiliencia, como factores condicionantes de los desastres, son socialmente construidas. No alcanza con analizar exclusivamente las causas del peligro, sus características, predicción y cuantificación (como en décadas anteriores se ha hecho); cada vez se presenta más imperiosa la necesidad de conocer las dimensiones de la vulnerabilidad, sus grados, sus patrones de distribución y los sectores diferenciales localmente situados. El estudio de la vulnerabilidad debe tener un enfoque holístico, puesto que no puede desvincularse del peligro o amenaza a la que se es vulnerable. El aporte del estudio de la resiliencia es relevante para la prognosis, en tanto la sociedad local puede organizase, dotarse de servicios, de mecanismos de respuesta en el territorio frente a los peligros.

En el presente artículo se examina la vulnerabilidad en su estructura causal (a través de la exploración por diferentes variables), su distribución y variabilidad espacial. Además, se presenta la relación con la estructura interna de la ciudad de Santa Fe y los sectores diferenciales, la aproximación a un elemento de resiliencia (rutas de transporte urbano de pasajeros) y una zonificación del riesgo, como síntesis del peligro y las vulnerabilidades diagnosticadas. El principal objetivo es generar una cartografía con la distribución de los niveles de vulnerabilidad socio-ambiental para 2010 y su relación con las vías de comunicación y transporte. Este diagnóstico se estima que puede contribuir a la gestión urbana en general, para replantear o revisar la asignación de usos del suelo al territorio, la apertura y desarrollo de nuevos sectores urbanos, la dotación de infraestructura, equipamiento y servicios. La cartografía que zonifica el riesgo relacionado a los eventos hidro-meteorológicos extremos, principal detonante de los desastres en el área de estudio, representa una herramienta precisa que localiza los sectores más afectados.

Las preguntas que han orientado este trabajo son: ¿Qué variables y dimensiones son relevantes para integrar el indicador de vulnerabilidad socio-ambiental para la ciudad de Santa Fe? ¿Cómo se distribuyen los niveles de vulnerabilidad socio-ambiental en el área de estudio? ¿Es posible distinguir alguna estructura o patrón de distribución? ¿Cuál es el rol de los transportes en la distribución de los niveles de vulnerabilidad? ¿Puede el transporte colectivo de pasajeros constituir un factor de resiliencia?

En el estudio de la relación del hombre con el medio y específicamente en el del riesgo, tanto desde la Geografía como de otras ciencias, se pueden identificar investigaciones de corte físico, social y sistémico, provenientes de diferentes ámbitos: Europa, Estados Unidos o América Latina. Tras una primera sección dedicada al desarrollo del contexto teórico del que se parte para el abordaje de los conceptos claves (vulnerabilidad, resiliencia, riesgo) y sus vinculaciones, se procede 
a la explicación de las características del área de estudio, se presenta el indicador sintético de la vulnerabilidad para el año 2010 conformado por las dimensiones individuales y personales de la población y aquellas públicas y/o constitutivas del entorno más cercano al hombre. Se aplica dicho indicador de vulnerabilidad o "índice de vulnerabilidad socio-ambiental (IVSA)" a la ciudad de Santa Fe, dando como resultado la distribución espacial de los niveles que conforman sectores de muy alta, alta, media, baja y muy baja vulnerabilidad. Gracias al uso de herramientas de los sistemas de información geográfica, estas zonas se relacionan con rasgos del territorio como la topografía y la hidrografía, elementos que brindan información sobre el peligro en el área de estudio. Particularmente, es de primordial interés analizar la vinculación de los sectores de vulnerabilidad con la infraestructura, vías de comunicación y servicios, puntualmente con el transporte público de pasajeros.

El diseño metodológico es de tipo cuantitativo, basado en un análisis multivariado simple a partir de datos censales provistos por INDEC (Instituto Nacional de Estadísticas y Censos) del último censo de 2010, combinado con información de otras fuentes de datos territoriales como IGN (Instituto Geográfico Nacional); el procedimiento consistió en análisis espaciales con herramientas del sistema de información geográfico Quantum 2.18.

\section{El derrotero de los estudios de riesgo y desastre: escuelas, perspectivas y antecedentes}

En el estudio del riesgo y los desastres se pueden reconocer distintas perspectivas, en función de la formación profesional de los autores o de los ámbitos geográficos donde se desarrollan (Europa, Estados Unidos o América Latina).

Los primeros trabajos hechos en Estados Unidos entre 1940 y 1980 por el geógrafo Gilberto White y sus colegas de la Universidad de Chicago, Robert Kates e lan Burton, para el manejo de las inundaciones, realizan un estudio social de los desastres, pionero por incorporar el factor humano en la ecuación. Estos trabajos derivan de las teorías funcionalistas de la Ecología Humana, promovidas por Harlen Barrows (1923), en el ámbito del behaviorismo (teorías del comportamiento). Una de las ideas centrales de la teoría de White es que las amenazas y los riesgos son producto de inadecuadas relaciones de convivencia entre la sociedad y su ambiente. Destaca la conveniencia de la combinación de medidas estructurales con cambios en el comportamiento humano, incentivados y regulados por normas y procesos de educación más congruentes con las amenazas del lugar. Los estudios de percepción de las amenazas de Kates de los '60 pertenecen a esta línea teórica. Los trabajos de Cutter (1989 y sucesivos) y sus colaboradores se inscriben en esta corriente.

Este enfoque funcionalista, también llamado ambiental o ecológico de los desastres, tuvo pretensiones de trasladar las herramientas teóricas generadas a los países en vías de desarrollo, hecho que fue duramente criticado, especialmente por autores de la escuela marxista de pensamiento como Torry y Watts, haciendo alusión a la falta de consideración de la cultura, historia, economía y sociedad en las propuestas referidas a la percepción del riesgo. Sin embargo, el aspecto de la relación sociedad-ambiente y las formas de ajuste y aprovechamiento del medio para el desarrollo será un punto de esta teoría que retomarán autores de las otras corrientes (como Wilches-Chaux, Blaikie, Westgate, Wisner, Caputo y Herzer, entre otros). 
También en Estados Unidos, en los '60 del siglo pasado, H. Quarantelli y R. Dynes llevaron adelante estudios sociológicos de desastres, poniendo énfasis en el conflicto y la respuesta social; esta corriente diferenciada de la de White y sus discípulos se identificó como Sociología de los Desastres (Lavell, 2004).

Una tercera corriente, hoy llamada 'escuela de la vulnerabilidad' surge en los '70 del siglo pasado, para contraposicionarse a las dos anteriores, de la mano de geógrafos de las ramas sociales y económicas de la Universidad de Bradford, Inglaterra: Wisner, Westgate y O'Keefe. Pertenecen a la corriente de pensamiento marxista, de la Geografía Radical forjada en los movimientos sociales de mayo Francés del '68. El argumento principal que esgrimen para explicar el subdesarrollo, echando mano de la teoría de la dependencia, es que los desastres son el resultado de procesos económicos y sociales globales, regionales y locales, que crean condiciones de existencia humana insostenibles frente a los eventos naturales extremos. "El problema de los desastres es el problema de la vulnerabilidad humana" (Lavell, 2004:12-13). Estos autores, desde el ámbito Europeo centraban su interés en trabajar temas de desarrollo rural en África. El problema de la sequía constituyó para ellos el punto de entrada al tratamiento global de los desastres. Blaikie y Cannon (1996), junto a Davis y Wisner, son otros autores ingleses que en los 90 ampliaron estos estudios de la vulnerabilidad al ámbito latinoamericano y asiático, aportando una significativa teoría social, con énfasis en la respuesta y recuperación de la comunidad luego del desastre.

El interés en torno al desarrollo y la producción social de la vulnerabilidad en sectores más carentes, resultó el elemento en común con la cuarta corriente: la de los 'estudios latinoamericanos de los desastres'. Comenzó en los años '80 del siglo pasado, movida por los daños provocados por las inundaciones que el fenómeno de El Niño había provocado en Perú, los terremotos en Colombia y México y otros eventos catastróficos de similares consecuencias. Así, autores como Andrew Maskrey y Gilberto Romero en Perú, influido por los aportes teóricos de los ingleses Turner y Davis, entre 1982 y 1983 realizaron un trabajo sobre la vulnerabilidad y el riesgo que el proceso de desarrollo urbano en Lima-Callao estaba generando, con la idea de que esta situación respondía a procesos particulares de urbanización dependiente, de la que América Latina estaba siendo objeto. Asumieron que la vulnerabilidad, como un factor condicionante de los desastres es socialmente construida. Por ello, se debe hacer un manejo popular de los desastres, conociendo la vulnerabilidad y planificando la mitigación.

Al mismo tiempo, compartiendo la premisa central de que los desastres no son naturales, sino que el factor humano siempre incide, que la vulnerabilidad es una construcción social y que "las amenazas son producto de una modalidad particular de desarrollo y sus formas de producción, consumo, distribución, asentamiento, expropiación de la naturaleza, etc". (Lavell, 2004: 8), en otros países latinoamericanos se daban a conocer investigaciones y teorizaciones. En Colombia, Omar Cardona (tomando aportes de Davis y Cuny), Velasquez y Meyer (integrantes del Observatorio Sismológico del Sur de Occidente), Wilches-Chaux; en México, Allan Lavell; en Bolivia, Argentina y otros países del cono sur, Caputo, Hardoy, Herzer (dentro de la órbita de CLACSO), todos tuvieron en común la integridad y holismo para el abordaje de los riesgos durante la década de los '80 y '90, deviniendo en la conformación de LA RED: Red de Estudios Sociales en Prevención de Desastres en América Latina. 
Esta evolución de los estudios brevemente referenciados, suscitados en los '70 y ‘ 80 del siglo 20, marca una clara falta de conexión entre las producciones que se daban en los países de habla inglesa y los latinoamericanos (salvo unas pocas excepciones, como los trabajos de Maskrey y Cardona). El enfoque del presente artículo no se circunscribe a una perspectiva en particular, sino que retoma aportes tanto de la ecología humana como de los estudios latinoamericanos, bajo la concepción de que pueden ser complementarios. De la ecología humana, el enfoque sistémico que permite identificar elementos y procesos dentro de los sistemas de riesgo; de los estudios latinoamericanos, la crítica a los modos de desarrollo basado en la reproducción de desigualdades y de condiciones de vida indignas e insostenibles.

Lejos de pretender ser exhaustivos, a continuación se hará referencia solo a algunos trabajos que constituyen los estudios antecedentes que en mayor medida brindaron luz a esta investigación, tanto en lo metodológico, como en lo conceptual. En primer lugar, no solo por tratarse de un estudio sobre la ciudad de Santa $\mathrm{Fe}$, sino por la riqueza de su enfoque y resultados, el escrito de Arrillaga, Grand, et al (2009), pone bajo la lupa la fuerte capacidad explicativa que las situaciones de exclusión social tienen del alto nivel de vulnerabilidad para el caso del territorio urbano santafesino frente a fenómenos hídricos extremos. Parten de una situación de amenaza constante por inundaciones y de unas condiciones de exclusión social acuciantes, diagnosticadas a partir de un índice sintético de vulnerabilidad socio-laboral en base a datos estadísticos del año 2001.

M. Con, et al. (2009) construyen un índice de vulnerabilidad social para el Gran Buenos Aires, en base a datos del CNPHyV (Censo Nacional de Población, Hogares y Viviendas) de 2001 de INDEC. Tomando los hogares como unidad bajo estudio, los resultados muestran una concentración de los grados más críticos de vulnerabilidad social en la zona sur de la ciudad, especialmente en las comunas linderas con el Riachuelo. Natenzon (2005) propone el índice de vulnerabilidad social como una evaluación cuantitativa, estadística (en base a datos del censo 1991, para un área comprendida por la Ciudad Autónoma de Buenos Aires y una serie de partidos de la Provincia de Buenos Aires ubicados en el litoral del Río de la Plata y sus tributarios), que permiten identificar en los 26 partidos diferentes grados de vulnerabilidad social. Concluye que las medidas públicas para el manejo de las inundaciones están desvinculadas de las políticas urbanas globales, siendo que la planificación urbana podría tender a la reducción del riesgo a través de diversas decisiones y acciones (las llamadas "medidas no estructurales"). Derivado de este trabajo surgen otras aplicaciones a riesgos de inundación y accidentes industriales en la baja cuenca del Plata, partidos San Nicolás y Berisso, incluyendo Capital Federal (Berrenechea, et. al., 2000).

Poniendo en cuestión el agravamiento de la situación de pobreza en América Latina, especialmente a partir de las políticas neoliberales de los '90, Minujin (1999) propone una clasificación de "excluidos, vulnerables e incluidos" a través del cálculo de un índice de vulnerabilidad social que combina el índice de necesidades básicas satisfechas y la línea de la pobreza.

Han medido la vulnerabilidad de la población ante desastres hidrometeorológicos extremos (inundaciones y sequías) Ibarrarán, et al (2014) a nivel estatal en México. Analizan los principales factores de la vulnerabilidad: infraestructura, mecanismos de protección de la población, organización de las instituciones formales e informales, grado de preparación para protegerse del evento natural y para afrontar las consecuencias. El índice de vulnerabilidad a escala estatal se 
complementa con ejercicios de simulación con el fin de evaluar el impacto de las políticas públicas en las diferentes variables seleccionadas.

Saliendo del ámbito latinoamericano, Cutter y Soleky (1989) a través del concepto de riesgo de los lugares examinan la distribución de los patrones de riesgo y los procesos subyacentes (Cutter, 2006). Esta perspectiva, desde un enfoque de la Geografía como Ecología Humana, investiga la vulnerabilidad, su estructura causal, su variabilidad espacial y el método para su reducción. Para ello desarrolla un modelo conceptual de implementación en el cual, partiendo de que el Riesgo y la Mitigación (que puede atenuar o amplificar el riesgo) interactúan para crear un Peligro Potencial inicial, filtrado a través del Contexto Geográfico y los Constructos Sociales, generando el primero la Vulnerabilidad Biofísica y el segundo la Vulnerabilidad Social, ambas se combinan y componen la "Vulnerabilidad del Lugar" (Cutter el al, 2000: 716), elemento del modelo que incide, a su vez, en el riesgo y la mitigación, cerrando este ciclo. La vulnerabilidad social en términos de Cutter incluye 17 variables para el estudio realizado en el condado de Georgetown, como ser: nivel económico, género, edad, raza y etnia, desempleo, propiedad de la vivienda, educación, estructura familiar, servicios médicos etc. (Cutter, et al, 2000). Con el objeto de medir la resiliencia social, otro estudio asegura que se puede incrementar la capacidad de respuesta frente a desastres a través de mejoras en las comunicaciones, toma de conciencia de los riesgos y su preparación, mediante el desarrollo e implementación de planes de desastres, compra de seguros, intercambio de información y conocimiento para el proceso de recuperación. El modelo de la resiliencia del lugar de desarrollo del desastre (DROP) (Cutter et al, 2008), presenta a la resiliencia como un proceso dinámico que depende de las condiciones antecedentes, de la severidad del desastre, del tiempo transcurrido entre la ocurrencia del evento peligroso y los factores exógenos. También de la experiencia de la comunidad en afrontar el desastre, en si se excede la capacidad de absorción de los impactos del desastre y en las respuestas adaptativas creadas: aprendizajes de eventos anteriores y estrategias de mitigación y preparación generadas.

Charles Booth, en su obra de fines del siglo XIX, basada en la observación y visita a los distintos barrios de Londres, realiza encuestas y levantamiento de datos cuantitativos sobre la situación de la pobreza urbana (relacionada a los impactos de la revolución industrial). La producción cartográfica permitió hacer un diagnóstico de las condiciones de habitabilidad según categorías, poniendo en evidencia que la pobreza en Londres era más acuciante que aquella que registraban los organismos de gobierno. Los aportes para reorientar la gestión fueron concretos: al relacionar la pobreza con la tercera edad se recomendaron pensiones a la ancianidad (Booth, 1903). Este puede considerarse un estudio de vulnerabilidad puesto que integra variables diversas que reflejan la situación de indefensión de la población ante ciertos peligros propios de esa época y de esa urbe industrial, como lo fueron la contaminación generada por las fábricas y las viviendas carentes de sistemas sanitarios y las epidemias que diezmaban la población.

\section{La vulnerabilidad y la resiliencia como elementos centrales en la teoría del riesgo}

El riesgo es un proceso que involucra necesariamente ciertos elementos; "el desastre es un producto" (Lavell, 2004: 8), mucho más que la mera consecuencia de la concreción de ese riesgo. 
Se define riesgo a "cualquier fenómeno de origen natural o humano que signifique un cambio en el medio ambiente que ocupa una comunidad determinada, que sea vulnerable a ese fenómeno" (Wilches-Chaux, 1993: 17). El desastre es la consecuencia de la manifestación de una amenaza en un territorio particularmente vulnerable a la misma. Su intensidad dependerá del grado de vulnerabilidad de la población, así como su capacidad de respuesta y recuperación (Wilches-Chaux, 1993; Foschiatti, 2009). Por ello, los daños ocasionados en un desastre serán directamente proporcionales al nivel de desarrollo de la comunidad afectada (Maskrey, 1993; Lavell, 2004; Blaikie y Cannon, 1996; Arrillaga, et al, 2009).

La concepción de la vulnerabilidad ha variado con el transcurso del tiempo, desde el interés en los componentes biofísicos del ambiente, a los sociales y humanos. "Por vulnerabilidad vamos a denotar la incapacidad de una comunidad para 'absorber', mediante el autoajuste, los efectos de un determinado cambio en su medio ambiente, o sea su 'inflexibilidad' o incapacidad para adaptarse a ese cambio, que para la comunidad constituye, por las razones expuestas, un riesgo. Como amenaza (para una comunidad) vamos a considerar la probabilidad de que ocurra un riesgo frente al cual esa comunidad particular es vulnerable" (Wilches-Chaux, 1993: 17).

En la construcción del concepto de vulnerabilidad del lugar, Cutter y sus colaboradores distinguen la vulnerabilidad biofísica (dada por el contexto geográfico, más asociada a las amenazas) de la social. Esta diferenciación puede resultar de utilidad para la planificación de las respuestas: "mientras que la vulnerabilidad física es reducida a través de la construcción de edificios resistentes a los desastres, los cambios en los usos del suelo, la restauración de humedales y cursos de agua, la marcada reducción de la vulnerabilidad social requerirá de la implementación de una mejora en la calidad de vida de los ciudadanos pobres" (Cutter, 2006: XXIV).

Desde la perspectiva ecosistémica, un desastre es "una situación de daño que altera la estabilidad de un ecosistema" (Foschiatti, 2009:16), estabilidad que depende de la capacidad para resistir, adaptarse o evolucionar. "En la prevención de los riesgos por reducción de la vulnerabilidad se debe actuar sobre las 5 áreas que la componen" (Foschiatti, 2009: 26): éstas son, según los aportes de Jorge Vargas, (2002:18) y Ana M. Foschiatti (2009: 20): 1-el grado de exposición (cantidad de tiempo expuesto al riesgo); 2- Protección (barreras permanentes); 3- Reacción inmediata (protección en el momento de la emergencia); 4- Recuperación básica (lograr condiciones esenciales de subsistencia); 5- Reconstrucción (recuperar iguales o mejores condiciones que las previas). La Protección y Reacción inmediata conforman la Homeostasis: autorregulación o capacidad del ecosistema de no afectarse y de sus elementos "para mantenerse en equilibrio o preservar sus características básicas, la vida de sus componentes y sus condiciones de subsistencia ante una actividad potencialmente destructiva o desestabilizadora" (Foschiatti, 2009: 25). La recuperación básica y la reconstrucción constituyen la Resiliencia, capacidad de recuperación del ecosistema de reponerse después de haber sido alterado por una actividad destructiva o desestabilizadora (Foschiatti, 2009:25). Para ambos autores, la homeostasis y la resiliencia integran la Resistencia, definida como "fortaleza o capacidad del ecosistema o de sus componentes para evitar, amortiguar o reponerse de los daños o la desestabilización" (Foschiatti, 2009: 25).

En síntesis, para Vargas, "la vulnerabilidad es el resultado del grado de exposición más la resistencia" (2002:17). En este sentido, la resiliencia es un componente integrante de la vulnerabilidad. 
La vulnerabilidad, concepto central de este trabajo, se constituye de diversas aristas. Para el abordaje de su complejidad Wilches Chaux, (1993) habla de 'vulnerabilidad global', entendida como una interacción de factores y características (internas y externas) que convergen en una comunidad particular y que conforman ese sistema dinámico. Son diversas las dimensiones que componen la vulnerabilidad global: natural, física, económica, social, política, técnica, ideológica, cultural, educativa, ecológica e institucional. Cada una de ellas constituye apenas un ángulo particular para analizar el fenómeno global.

En concordancia con los principales postulados en la obra "Los desastres no son naturales" de 1993, por los autores de LA RED (Red de Estudios Sociales en Prevención de Desastres en América Latina) (Maskrey, Cardona, Wilches-Chaux, García, Lavell, Romero) la postura de este trabajo parte de reconocer al riesgo como resultado de dos factores: la amenaza (o peligro) y la vulnerabilidad. El primero es esa condición latente que, de concretarse puede provocar daño; el segundo, se compone de los rasgos propios del individuo y su comunidad y del ambiente o entorno más cercano al hombre.

La vulnerabilidad y la resiliencia desde nuestro punto de vista, emergen como los elementos centrales en la teoría del riesgo, pero dentro de la ecuación, no como factores externos. La vulnerabilidad, con fuerte poder explicativo de las causas del riesgo y los desastres, constituye un elemento negativo porque denota debilidad, carencia o limitación de la comunidad, por tanto es definida como una incapacidad. Sin embargo, es un elemento dinámico, coyuntural, que puede modificarse. La capacidad explicativa del concepto de vulnerabilidad sirve para el diagnóstico, ya que brinda una noción del estado actual del territorio, de gran utilidad para su ordenación.

El término resiliencia proviene de la teoría general de sistemas y es empleado en diversos campos científicos, desde la Física, hasta la Psicología. En relación al estudio de los sistemas ecológicos, Holling (1973) define resiliencia a la propiedad que determina la persistencia de las relaciones en un sistema, a la "habilidad para absorber los cambios de las variables y el estado de esas variables" (Holling, 1973: 17), pudiendo pasar de un estado a otro manteniendo sus estructuras y funciones básicas.

En términos de Walker, et al (2004) la resiliencia es uno de los tres atributos de los sistemas socio-ecológicos que rigen la trayectoria futura; los dos restantes son la adaptabilidad y las transformabilidad. En semejante sentido que Holling, la resiliencia es definida como "la capacidad de un sistema de absorber los disturbios y reorganizarse al tiempo que se realiza un cambio para conservar esencialmente la misma función, estructura, identidad y retroalimentación" (Walker et al, 2004: 2). Estos autores analizan la velocidad de retorno al equilibrio y otros cuatro aspectos cruciales de la resiliencia para valorar el resultado del ciclo: latitud, resistencia, precariedad y panarquía (Walker et al, 2004). La adaptabilidad o "capacidad adaptativa" (Cutter et al, 2008: 600) se define como la "capacidad de los actores de un sistema de influir en la resiliencia"(Walker et al, 2004: 3), es decir, de gestionarla colectivamente, intencionalmente, pudiendo evitar el paso a un sistema indeseable o el éxito de volver a un régimen deseable. Respecto a este punto, se presenta una diferencia sustancial entre la adaptabilidad de los sistemas ecológico-sociales en general y aquellos que son susceptibles de padecer desastres, es decir los sistemas de riesgo: mientas que en los primeros, frente a una crisis se busca volver al equilibrio pre-existente, en los sistemas de riesgo, al ser sistemas de mayor complejidad, donde las crisis están dadas tanto por factores 
externos (amenazas) como internos (vulnerabilidades), propios del sistema, la pretensión no tenderá a volver al estado inicial, porque en él radica parte del problema que generó el desastre. Por ello, las respuestas del sistema (resiliencia, adaptabilidad y transformabilidad) siempre buscarán estados más sustentables, de menor exposición y vulnerabilidad. El éxito de estos mecanismos no estará en volver al equilibrio pre-existente, sino en la capacidad de respuesta del sistema, en el tiempo adecuado, en la resistencia, en la habilidad para reducir la vulnerabilidad y exposición y poder generar un nuevo estado más eficiente que el inicial, y por lo tanto de menor riesgo.

Los sistemas de riesgo son inestables, desequilibrados, propensos a crisis que son susceptibles de generar daños de consideración debido a fallas o estados indeseables de exposición y vulnerabilidad. Por ello, la fase de adaptabilidad buscará siempre estados de menor exposición.

La tercera fase del ciclo de los sistemas es la transformabilidad, capacidad de "crear un sistema fundamentalmente nuevo cuando las estructuras ecológicas, económicas o sociales hacen que el sistema existente sea insostenible" (Walker et al, 2004: 3) generando uno nuevo, más estable. Desde una concepción más amplia, estos tres atributos pueden funcionar de manera integrada en un mismo término que involucre la resiliencia, la adaptabilidad y la transformabilidad así definida por los autores antes referenciados. Este sería el concepto de resiliencia en un sentido amplio, tal como se concibe en este artículo: capacidad de un sistema de absorber los disturbios, reorganizarse, recuperarse, diseñar y gestionar la mitigación, preparación y recuperación, creando un sistema socio-ambiental nuevo, más sostenible y desarrollado (con menor exposición, vulnerabilidad y riesgo) y que eleve las condiciones de vida de la comunidad. La resiliencia se construye a partir de: experiencias previas de desastres (historia de desastres), conocimiento del medio socio-ambiental (económico, institucional, físico, etc.) y de las amenazas y vulnerabilidades del mismo, de la planificación y gestión de la mitigación y de las formas de respuestas ante eventos (obras de defensa, protocolos de actuación) y evaluaciones de la capacidad de respuestas y métodos de absorción.

Así como Cuny (1983), aporta argumentos sobre la manera en que los desastres pueden abrir una opción para el desarrollo, mediante la incorporación de la prevención y mitigación de riesgos en la reconstrucción, este enfoque de la resiliencia acepta el cambio como hecho inevitable e imprevisible a los que se enfrentan los sistemas y como una "oportunidad para mejorar el entorno y promover el desarrollo sostenible" (Tumini, 2016: 6), contribuyendo, a su vez, en un nueva visión del riesgo y del desastre.

Para Cutter, et al (2008) la resiliencia es "la habilidad de los sistemas sociales de responder y recuperarse a los desastres, incluyendo las condiciones inherentes que le permiten absorber los impactos y hacer frente a un evento, así como procesos adaptativos posteriores al evento que facilitan la capacidad del sistema social para reorganizar, cambiar y aprender en respuesta a una amenaza" ( $p$ 599). Cutter, et al refiere a dos cualidades de la resiliencia: "inherencia" (Cutter, et al, 2008: 600), como la perdurabilidad de las funciones del sistema durante la crisis; adaptabilidad, como la flexibilidad para responder frente al desastre. Inherencia y adaptabilidad pueden ser aplicadas para infraestructuras, instituciones $u$ organizaciones, tanto en sistemas sociales como en los económicos. 
En cuanto a la relación vulnerabilidad - resiliencia, existen autores que asumen que la primera incluye a la segunda (Vargas, 2002; Foschiatti, 2009); a la inversa, o que ambos conceptos son independientes, pero se relacionan (Cutter, 2006). Luego, otros autores definen vulnerabilidad con los mismos términos que otros resiliencia (Blaikie et al, 1996). La postura de Cutter et al, 2008, afirma que ambos términos no se oponen, son conceptos separados, pero muy relacionados.

La resiliencia, es un elemento de la ecuación del riesgo que atañe tanto al peligro como a la vulnerabilidad. Al peligro, lo amplifica o aplaca, especialmente a través de obras de mitigación que modifican la exposición actuando sobre el medio biofísico y tecnológico (construcción de defensas contra inundaciones, edificios antisísmicos); a la vulnerabilidad, la transforma dotando de habilidades a las comunidades para reaccionar ante un evento (protocolos de actuación en emergencias, conocimientos). Así, la resiliencia se presenta como el único elemento de la teoría del riesgo con signo positivo, con fuerte capacidad de cambio, transformación y mejora de todo el sistema, aporte fundamental para la prognosis, para la elaboración y gestión de la ordenación del territorio. Indica una capacidad, habilidad, potencial fortaleza de una comunidad para enfrentar una crisis, sobrepasarla, adaptarse a los cambios y aprovecharlos para el desarrollo.

\section{Los servicios y su capacidad de incidir en el territorio}

Si bien se reconoce una resistencia de los servicios a la conceptualización disciplinar existe consenso en los "lazos estructurales entre la producción y los servicios" (Moreno Jiménez; Escolano Utrilla, 1992: 15); el transporte, distribución, banca y seguros son pasos intermedios en las cadenas productivas. También se emplean para consumo intermedio y final. Según el criterio de interés pueden recogerse diferentes clasificaciones de servicios, por ejemplo dentro de los urbanos básicos para la vida de los ciudadanos, que aseguran las necesidades más primarias, se encuentran los esenciales (luz, agua, drenaje, recogida de la basura, transporte de pasajeros) y asistenciales (educación, salud, seguridad). Éstos pueden ser públicos, privados o una combinación de ambos, "bajo control administrativo del estado" (Moreno Jiménez; Escolano Utrilla, 1992: 63), categoría más pendiente de criterios de accesibilidad, que de rentabilidad. Los servicios (junto con su infraestructura y equipamientos) resultan claves debido a que tienen la capacidad de incidir activamente en las relaciones de los individuos y agentes socio-económicos con el territorio. Es posible construir o remodelar un territorio determinado, estructurar o reconfigurar una ciudad e incidir en su medio ambiente, planificando, organizando, dotando y mejorando la prestación de servicios (Pérez-Foguet, 2005). Este será uno de los caminos que deberán tomar los programas para la reducción de la vulnerabilidad.

En el contexto de postmodernidad, la importancia de los servicios en el desarrollo económico y tecnológico de las regiones y países es crucial. "Sin servicios, las economías quedan varadas y a expensas del exterior. Son varias las clases de servicios que se juzgan como indispensables para el desarrollo socioeconómico. En primerísimo lugar las infraestructuras de servicios: transportes, comunicaciones, educación, salud; la posesión de estos servicios es un prerrequisito para el progreso. Con ellos, los servicios de conexión, especialmente los que proveen inputs intermedios a la producción de bienes y otros servicios: banca, finanzas, seguros, comercio, ingeniería, consultoría, investigación y desarrollo, etc.; su difusión y grado de actualidad tecnológica afectan a la competitividad y sinergia del sistema económico. Finalmente, los servicios de información: bases de datos informatizadas, tratamiento automático de la información, etc." (Moreno Jiménez, et. al, 1992: 16). 
La carencia de servicios en ciertos sectores urbanos es un rasgo que contribuye al fenómeno de la informalidad urbana, sumándose a otras situaciones como la irregularidad en la ocupación del terreno o la vivienda; estas necesidades son suplidas a través de la auto-provisión de los servicios básicos, añadiendo un problema más acuciante: la generación de espacios de inseguridad, alto riesgo de accidentes u otros modos de afectación a la salud y la vida (caso de conexiones de luz ilegales, uso de leña para cocinar, volcado de efluentes cloacales en la vía pública).

Los servicios en general, como elemento estructurador de los territorios, pueden incorporarse al análisis a través de los diagnósticos de la vulnerabilidad, en los casos en que se carece o son inaccesibles, o de la resiliencia, en tanto factor que se planifica para integrar un sector urbano a los mecanismos de respuesta frente a las crisis.

El transporte, su estructura y función, inciden directamente en la resiliencia debido a que posibilitan la movilización de personas, bienes y servicios durante y después de un evento.

\section{El área de estudio: situación y emplazamiento, estructuración y riesgo.}

Santa Fe, capital de la provincia homónima es una ciudad intermedia de 391.231 hab en 2010 (INDEC). Es el municipio principal del Gran Santa Fe, área metropolitana de 492.882 habitantes

Figura $\mathrm{N}^{\circ} 1$

Distrito Santa Fe. Situación y emplazamiento.

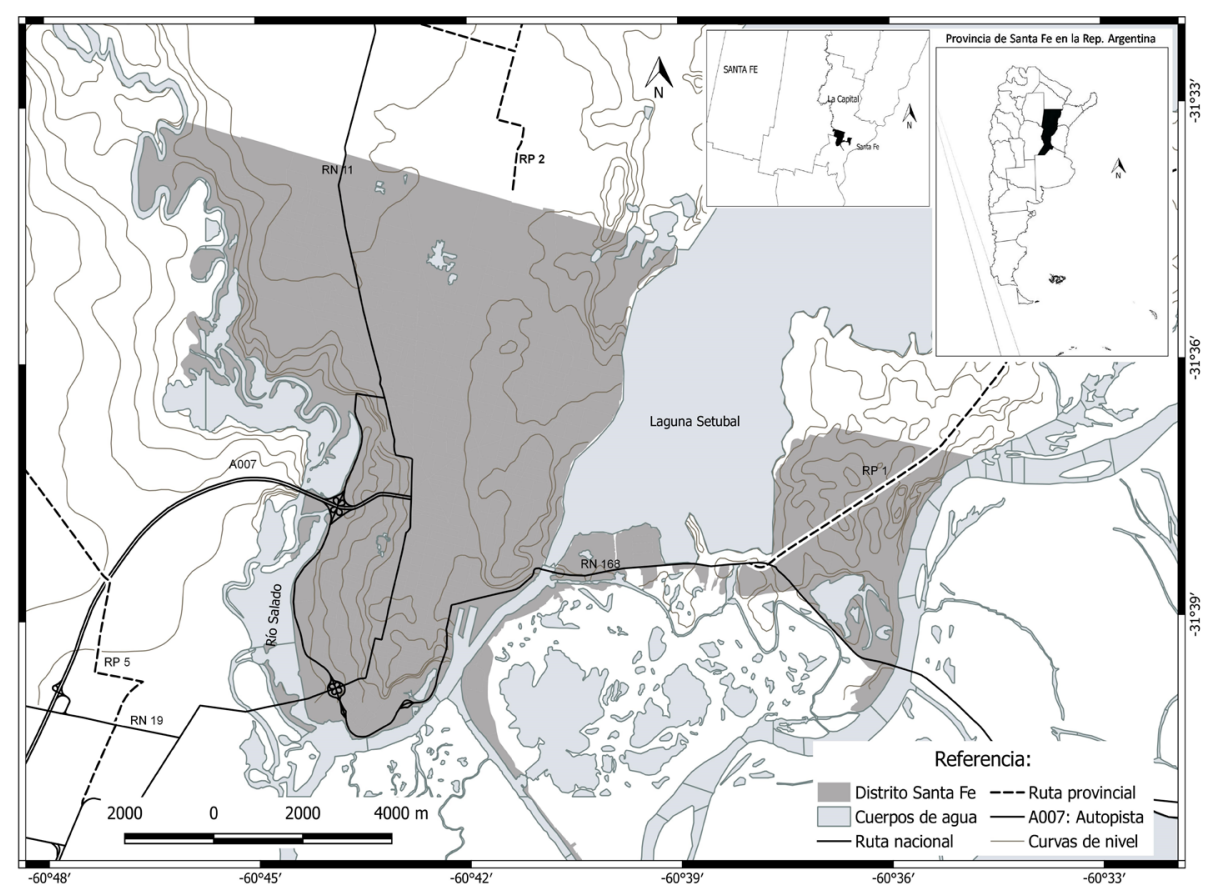

Fuente: Elaboración propia en base a datos del IGN y del IPEC. 
que ocupa el 8vo lugar en el sistema urbano argentino. Esta urbe ha tenido un significativo crecimiento desde mediados del siglo XIX hasta mitad del XX, vinculado a la actividad portuaria y a su función administrativa como capital. El crecimiento se reduce década tras década hasta llegar a una tasa media anual baja, del orden del 0,6\% para 2001-2010. La expansión del hecho urbano en sentido centrífugo, se orientó principalmente hacia el norte, puesto que al sur, al este y al oeste su espacio se encuentra acotado por el río Salado y el Sistema Lagunar Setúbal - Leyes (Figura $\mathrm{N}^{\circ}$ 1). La columna vertebral de ese desplazamiento fueron los grandes ejes viarios, que corriendo de norte a sur, abrieron nuevas urbanizaciones a sus alrededores: Av. Gral. Paz, Av. Aristóbulo del Valle, Av. Facundo Zuviría, Av. López y Planes (al sur), luego se transforma en Av. Gral. Peñaloza y finalmente Av. Blas Parera.

\section{Propuesta metodológica: indicador sintético de vulnerabilidad socio-ambiental.}

Entendiendo a la vulnerabilidad como las condiciones sociales, económicas y ambientales de la comunidad, esta construcción metodológica propone ciertas dimensiones que atañen a la población del área de estudio, identificando aquellas variables que puedan incidir de manera más significativa en las condiciones de vida. El índice de vulnerabilidad socio ambiental tiene la particularidad de ser integrador por cuanto incluye dimensiones educativas, demográficas (relativa al ciclo de vida), de condiciones habitacionales, de infraestructura, equipamientos y servicios, pobreza, etc. que constituyen rasgos de la propia persona y de su entorno más cercano; la síntesis y sistematización de la información permite que el producto resultante sea factible de ser empleado en la toma de decisiones. Las variables consideradas representativas de los factores sociales y ambientales son adecuadas para el área de estudio específicamente.

El proceso de construcción de un IVSA se compone de una serie de etapas: selección de variables, recopilación de datos de fuentes confiables (en este caso, IPEC-INDEC), creación de la matriz de datos, normalización - estandarización de las variables, cálculo del puntaje de clasificación espacial de costo y beneficio, generación del índice. El IVSA permite detectar diferentes niveles que son categorizados en quintiles y representados cartográficamente para su análisis. "La obtención de puntajes de clasificación espacial es una metodología de análisis multivariado simple que se basa en la estandarización de variables con la finalidad de obtener un valor resumen que se mapea y del cual se analiza su distribución espacial" (Buzai, 2014: 165). El procedimiento consta de la estandarización de los datos de cada variable (el cálculo del puntaje omega lleva los valores originales a un rango que va del 0 a 1, volviéndolos perfectamente comparables) ${ }^{2}$.

Existen tres tipos de variables: de costo (que expresan situaciones desfavorables por ejemplo el analfabetismo), de beneficio (expresión de situaciones favorables como el nivel universitario completo) y neutras (que no representan en sí misma ninguna de las dos anteriores, como cantidad de población). Dado que el índice de vulnerabilidad refleja una situación de desfavorabilidad ante el territorio que ocupa la población estudiada, se invierte la fórmula para el cálculo del puntaje de clasificación espacial donde las variables de costo se tratan como de beneficio y viceversa.

Omega = xi-m/M-m Donde omega es el puntaje estándar del i-ésimo dato, xi es el dato original a ser estandarizado, mientras que $\mathrm{m}$ y M son respectivamente el menor y mayor valor de la variable. 
De este modo, en un rango de 0 a 100, los valores que se acerquen al 100 tendrán un mayor nivel de vulnerabilidad y por ende peores condiciones socio-ambientales.

Entonces, según el tipo de variable se aplica:

Puntaje de costo para índice de vulnerabilidad $=(x i-m / M-m) * 100$

Puntaje de beneficio para índice de vulnerabilidad $=1-(\mathrm{xi}-\mathrm{m} / \mathrm{M}-\mathrm{m}) * 100$

(Donde $\mathrm{xi}$ es el dato original a ser estandarizado, mientras que $\mathrm{m}$ y $\mathrm{M}$ son respectivamente el menor y mayor valor de la variable).

Finalmente, el cálculo del promedio de las variables representa el puntaje de clasificación espacial. Éste constituye el IVSA que al clasificarse (por quintiles) da cuenta de la distribución espacial en los siguientes niveles: Muy alto, Alto, Medio, Bajo, Muy bajo.

\section{Las variables componentes del índice de vulnerabilidad socio-am- biental de la ciudad de Santa Fe.}

Las variables son aquellos atributos, relaciones o contextos considerados relevantes para describir a las unidades de análisis, radios censales en este caso. Toda variable es un criterio de clasificación seleccionado especialmente a los fines del estudio. La integración de las variables que a continuación se describen, definen el IVSA. A los efectos de exponer los diferentes aspectos que aportan a la vulnerabilidad, para el objetivo de este estudio se tomaron en cuenta 12 variables (Cuadro N 1); se recurrió a datos del IPEC correspondientes al censo 2010.

\section{Cuadro $N^{\circ} 1$}

Dimensiones y variables que componen el Índice de Vulnerabilidad Socio ambiental.

\begin{tabular}{|c|c|c|}
\hline DIMENSIÓN & Variable & Indicador \\
\hline $\begin{array}{l}\text { DEMOGRÁFICA } \\
\text { CICLO DE VIDA }\end{array}$ & $\begin{array}{l}\text { 1.Población de menos de } 15 \text { años y de } 65 \text { años } \\
\text { y más }\end{array}$ & Ciclo de vida \\
\hline \multirow[t]{2}{*}{ EDUCACIÓN } & $\begin{array}{l}\text { 2.Porcentaje de población de } 4 \text { años y más que } \\
\text { no sabe leer ni escribir. }\end{array}$ & \multirow[t]{2}{*}{ Nivel de instrucción } \\
\hline & $\begin{array}{l}\text { 3.Población de } 15 \text { años y más que cursa o cursó } \\
\text { nivel educativo primario. }\end{array}$ & \\
\hline \multirow[t]{2}{*}{ SERVICIOS -SALUD } & $\begin{array}{l}\text { 4. Hogares habitados con agua para beber y co- } \\
\text { cinar procedente de red pública. }\end{array}$ & \multirow[t]{2}{*}{ Calidad sanitaria } \\
\hline & $\begin{array}{l}\text { 5. Hogares habitados con baño con desagüe de } \\
\text { inodoro a red pública. }\end{array}$ & \\
\hline \multirow[t]{2}{*}{ HABITACIONAL } & $\begin{array}{l}\text { 6. Hogares habitados con régimen de tenencia } \\
\text { propietarios de la vivienda y el terreno. }\end{array}$ & \multirow[t]{2}{*}{ Calidad habitacional } \\
\hline & 7.Vivienda particulares tipo rancho & \\
\hline \multirow[t]{3}{*}{$\begin{array}{l}\text { EQUIPAMIENTO } \\
\text { SERVICIOS }\end{array}$} & $\begin{array}{l}\text { 8. Hogares habitados que no tienen computa- } \\
\text { dora }\end{array}$ & \multirow[t]{3}{*}{$\begin{array}{l}\text { Nivel de equipamientos } \\
\text { y servicios }\end{array}$} \\
\hline & 9.Hogares habitados que no tienen celular & \\
\hline & 10. Hogares habitados que poseen gas de red & \\
\hline
\end{tabular}




\begin{tabular}{|l|l|l|}
\hline DIMENSIÓN & \multicolumn{1}{|c|}{ Variable } & \multicolumn{1}{|c|}{ Indicador } \\
\hline POBREZA & $\begin{array}{l}\text { 11.Viviendas particulares habitadas según cali- } \\
\text { dad de materiales IV. }\end{array}$ & $\begin{array}{l}\text { Condiciones de vida - } \\
\text { carencias }\end{array}$ \\
\cline { 2 - 3 } & $\begin{array}{l}\text { 12.Hogares habitados con 2 o más personas por } \\
\text { cuarto }\end{array}$ & \\
\hline
\end{tabular}

Fuente: Elaboración propia.

La población pasiva, constituida por los pasivos transitorios (menores de 15 años) y pasivos definitivos (de 65 años y más) representa aquellas personas que tienen elevados niveles de indefensión y que dependen de otros ante la ocurrencia de fenómenos adversos.

La dimensión educativa se justifica desde el reconocimiento de la estrecha relación que existe entre nivel de instrucción y la posibilidad de inserción laboral, donde las posibilidades son mayores para las personas más cualificadas y mejor formadas. La contracara es el bajo nivel educativo y la situación de retroceso y marginalidad económica y social a la que ésta lleva a la persona, cercenando las posibilidades de desarrollo. La población de 4 años y más que no sabe leer ni escribir representa una variable indicativa de una situación desfavorable, pues es un reflejo de las carencias en las herramientas que brinda la educación al individuo para formar parte de la vida en sociedad, para la integración al mercado laboral formal, o cualquier otro proyecto. En semejante sentido la población de 15 años y más de edad que cursa o cursó nivel educativo primario estaría señalando condiciones desfavorables que incrementan los niveles de vulnerabilidad; se toma esa franja etaria (recurriendo al agrupamiento de edades quinquenales del INDEC) por ser la que está excedida en la edad para concurrir a la escuela primaria obligatoria.

En la dimensión servicios abocados a la mejora de la salud, que contribuyen a la calidad sanitaria o bien señalan déficit en este ámbito, se definen dos variables: hogares habitados con agua para beber y cocinar procedente de red pública, imprescindible para el logro de una buena condición sanitaria, al asegurarse la calidad de este bien primordial. Los hogares habitados cuyo baño posee inodoro con descarga a red pública (cloaca) dan cuenta de un estado sanitario óptimo en cuanto al tratamiento de las aguas servidas, previniendo la proliferación de enfermedades derivadas de un ambiente contaminado con este tipo de residuos.

En la dimensión habitacional, son indicativas de niveles diferenciales de calidad habitacional las variables hogares habitados con régimen de tenencia propietarios de la vivienda y el terreno (quienes no lo son estarían en una situación de inestabilidad y de indefensión ante un derecho primordial de la persona como es la vivienda, teniendo muchas veces que caer en situaciones de habitabilidad irregular o precaria) y viviendas particulares tipo rancho (según el INDEC rancho es una vivienda con salida directa al exterior -sus habitantes no pasan por pasillos o corredores de uso común- construida originalmente para que habiten personas; generalmente tiene paredes de adobe, piso de tierra y techo de chapa o paja; se considera propia de áreas rurales).

Relacionados a la calidad habitacional, pero dependiente del equipamiento y de los servicios con los que cuentan las personas se optó por tres variables: hogares habitados que no tienen computadoras, ni celular como dos elementos tecnológicos destinados a la comunicación, a la integración, a la información y a la instrucción, claves en el contexto de la sociedad de la informa- 
ción en la que nos situamos. La tercera refiere a un elemento de diferente naturaleza como lo es el gas de red empleado para cocinar.

En la dimensión de la pobreza, como indicadores de condiciones de vida - carencias se eligieron dos variables: viviendas particulares habitadas según la calidad de materiales IV (refiere a la vivienda que presenta materiales de baja calidad en pisos y techos) y hogares hacinados (con 20 más personas por cuarto). Éstas caracterizan al entorno más cercano al hombre, el ámbito de las relaciones primarias, de la construcción de la identidad social, del desarrollo de la persona como individuo y ciudadano.

\section{Cálculo del índice de vulnerabilidad socio-ambiental y los patrones de localización en la ciudad de Santa Fe}

Definidas las variables, transformadas las tasas en números-índice parciales (puntajes Omega), según el tipo de variable, calculados los puntajes de clasificación espacial, se obtiene un promedio simple que oscila entre el 0 y 100. Éstos expresan los valores de vulnerabilidad (Figura $N^{\circ} 2$ ), entre los que se acerquen a 100 serán poseedores de mayores niveles de vulnerabilidad, indicativo de peores condiciones de vida y de exposición e indefensión ante la ocurrencia de eventos peligrosos.

Figura $\mathrm{N}^{\circ} 2$

Niveles de vulnerabilidad socio-ambiental por radios censales, Distrito Santa Fe, 2010.

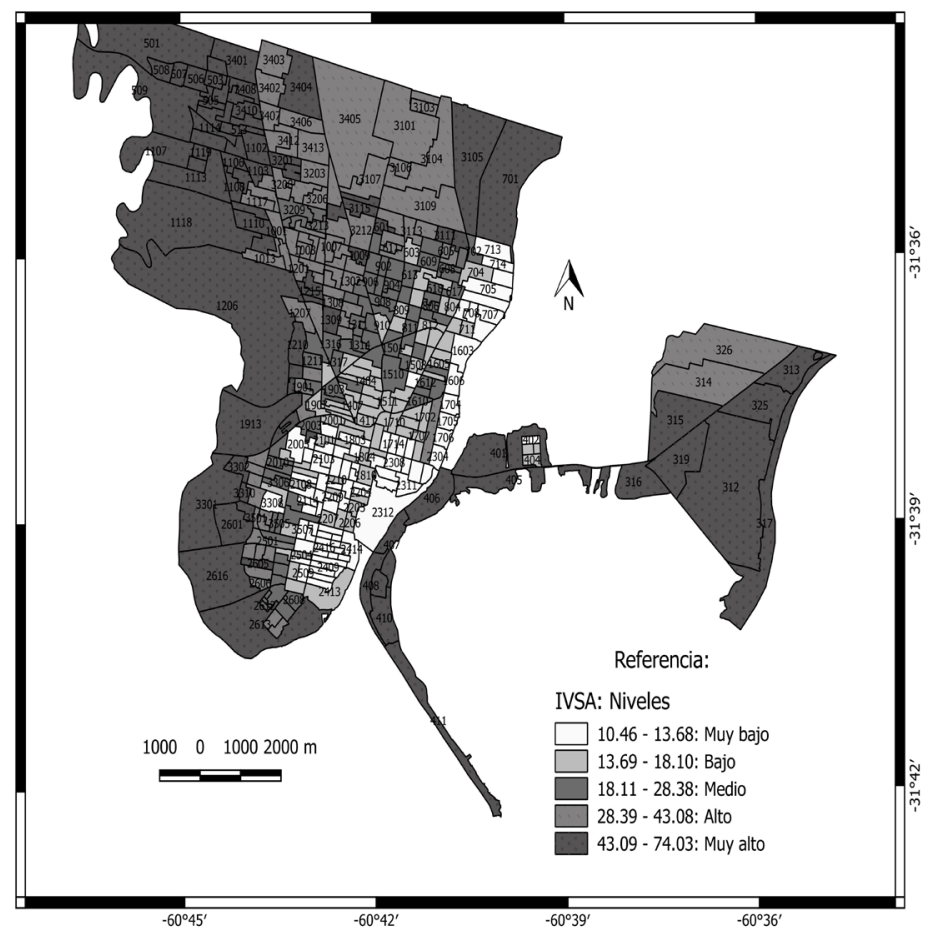

Fuente: Elaboración propia. 
La Figura $\mathrm{N}^{\circ} 2$ presenta una clasificación por quintiles, quedando delimitadas 5 clases en las que se ubican el $20 \%$ de las unidades espaciales (radios censales); en sentido de menor a mayor favorabilidad dichas clases son: Niveles de vulnerabilidad muy alto, alto, medio, bajo y muy bajo. El IVSA para todo el distrito Santa Fe es de 28,80.

Figura $\mathrm{N}^{\circ} 3$

Distribución de los datos de niveles de vulnerabilidad socio-ambiental en Santa Fe, en 2010.

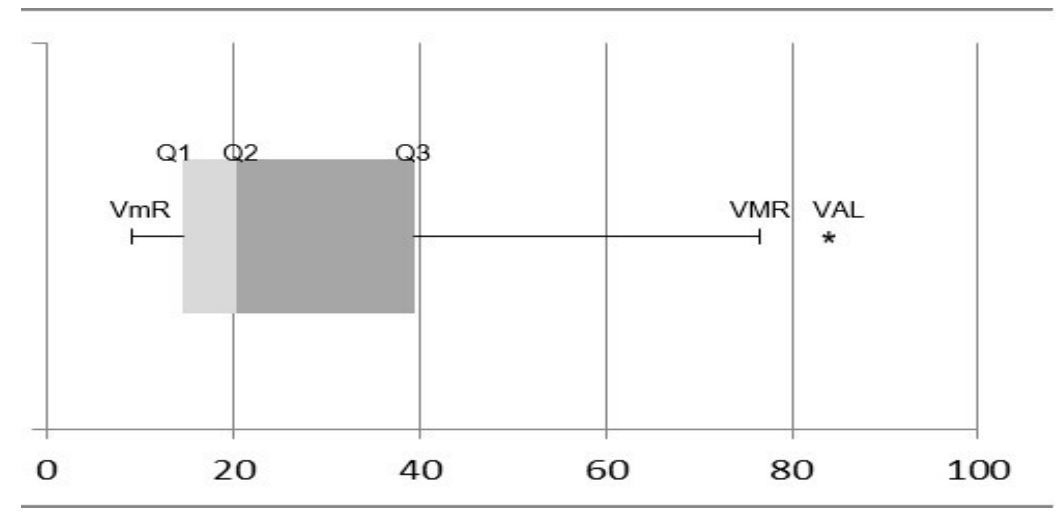

Referencias: VmR: Valor mínimo real=10,46; Q1=14,69; Q2: mediana= 20,28; Q3= 39,39; VMR: Valor máximo real= 74,03; VAL: Valor atípico leve $=83,85$.

Fuente: Elaboración propia.

La distribución del box-plot generado (Figura $\mathrm{N}^{\circ} 3$ ) señala una gran concentración de radios censales en los valores más bajos de vulnerabilidad, hasta la mediana, y a partir de allí una gran dispersión de los radios en valores de VSA más altos y con gran diversidad, encontrándose un valor atípico leve $(83,85)$. Los valores atípicos representan aquellos que numéricamente se distancian del resto de los datos. Corresponde al radio 318 localizado en Colastiné Sur, en el sector denominado ribereño (sureste).

La Figura № 2 muestra que la disposición de áreas de vulnerabilidad es claramente radiocéntrico imperfecto, adaptado a la presencia de los cuerpos de agua (el corazón de la estructura circular está ceñido a la laguna Setúbal, cortando los demás sectores): el área del micro y macro centro santafesino, del nuevo puerto de Santa Fe y la línea de radios que acompañan la costanera capitalina poseen una vulnerabilidad muy baja. Éste constituiría el cuore de la estructura radiocéntrica. En sentido centrífugo, le siguen los sectores de vulnerabilidad baja y media, disposición alterada en casos por espacios vinculados a los ferrocarriles que entraron en decadencia y alojaron población con niveles de vulnerabilidad más altos (ejemplo radio 1703). El sector de vulnerabilidad alta se presenta de manera discontinua en transición a los de vulnerabilidad muy alta, con un engrosamiento hacia el norte de la ciudad. La vulnerabilidad muy alta es un área continua de considerable grosor en el oeste santafesino y en algunos radios (disposición insular) en el norte. Los distritos de la ribera (sector este), con excepción del barrio El Pozo (402 al 404) registran una vulnerabilidad alta y muy alta, denotando serias deficiencias. 
La categorización hecha en niveles de vulnerabilidad y su cartografía, permite detectar quiénes son más vulnerables a los peligros concretos de este tiempo y espacio. En el ámbito urbano, son más vulnerables los habitantes del llamado 'marginal oeste' de la ciudad de Santa Fe, barrios anegadizos, ubicados en el valle de inundación del Salado, villas miseria conformadas por viviendas precarias, con diferentes modalidades de irregularidad; también los radios de la ribera, sector este, más allá de la laguna Setúbal, como Colastiné Sur, Alto Verde, Vuelta del Paraguayo, que carecen de condiciones óptimas de vida. En el espacio rural y rururbano de los tres distritos, registran una vulnerabilidad muy alta o alta aquella población dedicada a actividades en continua crisis como los horticultores, ganaderos, criadores de pollos o agricultores (pequeños productores), quienes deben padecer los vaivenes de los mercados y las penurias asociadas a los eventos meteorológicos extremos: granizadas, vendavales, anegamientos.

La localización y relación de los diferentes sectores de vulnerabilidad identificados guarda íntima relación con algunos rasgos esbozados en los modelos de estructura interna de las ciudades latinoamericanas de geógrafos alemanes, estadounidenses y latinoamericanos. Del modelo de ciudad latinoamericana de Bähr y Mertins (1981), Mertins (1995), en Santa Fe se visualiza claramente una estructura antigua de anillos concéntricos configurados en el período colonial, que para el caso de estudio se localiza al sur-este del ejido urbano, 'ceñido' a la confluencia de los cuerpos de agua (desembocadura del río Salado en el riacho Santa Fe), coincidente con los barrios de muy baja vulnerabilidad, con buena dotación de servicios y una imagen urbana de gran valor simbólico y natural; una estructura moderna sectorial, generada a partir de 1930, que corresponde a la expansión hacia el norte, localizándose las clases más acomodadas santafesinas en la ribera oeste de la laguna Setúbal (de Griffin y Ford, 1980 retomado de Hoyt, 1939). Inciden en ese impulso de avance, la apertura de las principales avenidas que corren de sur a norte. El tercer patrón que se superpone presenta una estructura celular periférica formada por barrios informales (ilegales 0 semi-legales), barrios residenciales cerrados y nuevas centralidades (shoppings) a partir de los 90 del siglo pasado. Entre el centro y la periferia Ford (1996) ubica las áreas de madurez y acrecentamiento que corresponderían a los niveles bajos y medios de VSA, zonas mejor equipadas. La periferia, en la que predomina la vulnerabilidad alta y muy alta tiene una estructura celular (Bähr y Mertins (1981), insular (Janoschka, 2002), fragmentada (Bordof, 2003).

Cuadro $\mathrm{N}^{\circ} 2$

Cantidad y proporción de población en 2010 componente de cada sector de vulnerabilidad socio-ambiental.

\begin{tabular}{|l|c|r|r|}
\hline Niveles de VSA & Rango de valores de VSA & Población total 2010. & \% población total 2010 \\
\hline Muy Bajo & 10,46 a 13,68 & 54.342 & 13,89 \\
\hline Bajo & 13,69 a 18,10 & 61.132 & 15,63 \\
\hline Medio & 18,11 a 28,38 & 68.821 & 17,59 \\
\hline Alto & 28,39 a 43,08 & 97.880 & 25,01 \\
\hline Muy Alto & 43,09 a 74,03 & 109.056 & 27,88 \\
\hline
\end{tabular}

Fuente: Elaboración propia en base a datos de IPEC y de la categorización propia, 2010. 
El cuadro $N^{\circ} 2$ ofrece información de la cantidad de población afectada por cada categoría: se observa que a los niveles mayores de vulnerabilidad corresponden mayores proporciones de población santafesina, es decir: que en los sectores de la ciudad con niveles más altos de vulnerabilidad habita mayor cantidad de personas. A medida que disminuyen los niveles de VSA de la tabla, la proporción de población afectada también disminuye, dando evidencias claras de la situación de exposición que se vive en 2010.

Dado que el indicador generado se compone de variables de diversa índole, resulta relevante el análisis de la participación de éstas en el valor promedio del área de estudio.

Se pueden clasificar las variables en privadas (expresan rasgos de la propia persona) y en públicas (expresan características del entorno más cercano, exteriores al individuo que inciden en las condiciones de vida).

\section{Cuadro $\mathrm{N}^{\circ} 3$}

Incidencia de las variables e indicadores en el índice de vulnerabilidad socio-ambiental, 2010.

\begin{tabular}{|l|c|c|c|}
\hline Dimensiones & Indicador & IVSA & Tipo de variable \\
\hline Demográfica - Ciclo De Vida & Pasivos & 67,50 & Privada/personal \\
\hline \multirow{2}{*}{ Educación } & Analfabetos & 29,56 & Privada/personal \\
\cline { 2 - 4 } & Primario & 26,41 & Privada/personal \\
\hline \multirow{2}{*}{ Servicio - Salud } & Agua & 8,74 & Pública \\
\cline { 2 - 4 } & Cloaca & 43,34 & Pública \\
\hline \multirow{2}{*}{ Habitacional } & Propietario & 22,54 & Privada/personal \\
\cline { 2 - 4 } & Rancho & 1,43 & Privada/personal \\
\hline \multirow{2}{*}{ Equipamiento - Servicios } & Carece Compu & 47,39 & Privada/personal \\
\cline { 2 - 4 } & Carece Celu & 24,07 & Privada/personal \\
\cline { 2 - 4 } & Gas & 49,49 & Pública \\
\hline \multirow{2}{*}{ Pobreza } & Calmat IV & 2,02 & Privada/personal \\
\cline { 2 - 4 } & Hacinamiento & 23,02 & Privada/personal \\
\hline & IVSA & 28,80 & \\
\hline
\end{tabular}

Referencias:

Grado de incidencia de la variable en el IVSA.

Alta $(45,44$ a 67,50$)$

Media $(23,44$ a 45,43$)$

Baja $(1,43$ a 23,43$)$

Fuente: Elaboración propia.

La variable que mayor incidencia tiene en el IVSA, según lo indica el Cuadro $\mathrm{N}^{\circ} 3$ es la relativa a la dimensión demográfica-ciclo de vida, expresada en la población pasiva, variable de tipo personal o individual. En segundo lugar, le siguen: disponibilidad de gas de red (variable pública o relativas al entorno de la persona) y la carencia de computadora, correspondiente a la dimensión equipamiento y servicios, ésta última representa un elemento tecnológico indispensable tanto 
para la comunicación y vida social, como para el desarrollo de actividades productivas, especialmente las más avanzadas y competitivas. Éste, al tratarse de un objeto que depende de la capacidad económica, es un indicador indirecto del nivel de ingresos del grupo familiar.

En términos generales, el PNUD, (2014) considera vulnerables los niños, ancianos, mujeres, pobladores de grupos originarios, migrantes o desplazados y discapacitados. En la primera infancia la pobreza altera el curso normal del desarrollo: más de uno de cada cinco niños en países en desarrollo vive en condiciones de pobreza económica absoluta y es vulnerable a la malnutrición. De cada 100 de estos niños, 7 no superarán los 5 años de edad, no se registrará el nacimiento de 50, 68 no recibirán educación en la primera infancia, 17 nunca se matricularán en la escuela primaria, 30 sufrirán retraso en el crecimiento y 25 vivirán en la pobreza (PNUD, 2014). Una alimentación, servicios de saneamiento e higiene inadecuados aumenta el riesgo de infecciones y retrasos del crecimiento, sumado al grave flagelo de la desnutrición. Debido a la falta de una nutrición, asistencia médica y estimulación básica encaminada al fomento de un crecimiento sano, muchos niños pobres llegan a la etapa escolar sin estar preparados para el aprendizaje, obteniendo bajos rendimientos o abandonando los estudios (Albino, 2010). Pronto se acentúan las diferencias en cuanto a los conocimientos.

La pobreza y la exclusión social son problemas para aquellos que están envejeciendo, en especial porque alrededor del $80 " \%$ de la población mundial de personas mayores no cuenta con una pensión y depende del trabajo y la familia para recibir ingresos. En la vejez, la pobreza suele ser crónica, puesto que la falta de oportunidades y seguridad económicas en anteriores etapas de la vida convergen en los últimos años de las personas (PNUD, 2014).

Tienen incidencia media en el índice una variables relativa a los servicios de salud: hogares con acceso a cloaca, las dos variables de la dimensión educación y carencia de celular, perteneciente al subgrupo de equipamiento y servicios. La ciudad tiene un nivel bastante bueno en la dotación de agua, pero presenta una deuda considerable en materia de cloacas. Finalmente, las variables que menor incidencia tienen son viviendas tipo rancho, construidas con materiales no resistentes, hogares con agua de red, propiedad de la vivienda y terreno y carencia de celular.

\section{Zonificación del riesgo y factores de resiliencia: las redes de comunicación y transporte.}

Entendido el riesgo como la confluencia, en el tiempo y en un espacio concreto, de una amenaza (en este caso fenómenos hidrometeorológicos extremos) y de una población vulnerable a ésta, en el presente apartado se propone su zonificación. Para ello, en la Figura $N^{\circ} 4$, al mapa de los niveles de vulnerabilidad socio-ambiental se incorporan los cursos de agua y curvas de nivel con cotas diferenciadas: cotas bajas (en línea entrecortada) son las de 16 msnm e inferiores (ubicadas en adyacencias de los cursos de agua, Río Salado, Laguna Setúbal, brazo Colastiné, indicativas de que se está en el ámbito de los lechos de inundación o cubetas de agradación) y cotas medias (en línea continua), las que superan los $16 \mathrm{msnm}$, correspondientes a albardones propios del ambiente ribereño o terrenos de interfluvios). A través de las herramientas de análisis espacial que posibilita el uso de SIG, se obtiene esta nueva categoría, producto de la yuxtaposición en el espacio de dos variables de interés. Se puede observar una coincidencia entre las cotas bajas y la 
disposición de los sectores de vulnerabilidad media, alta y muy alta, especialmente en el marginal oeste, sector noreste y este-ribereño. Este análisis permite arribar a la conclusión de que dicha población es muy vulnerable a los fenómenos hidrometeorológicos y a las crecidas periódicas y extraordinarias de los cursos de agua. Esos radios, en los que confluyen condiciones de terreno bajo, anegadizo con sectores de vulnerabilidad socio-ambiental media, alta o muy alta, constituyen territorios urbanos de alto riesgo.

Figura $\mathrm{N}^{\circ} 4$

Zonificación del riesgo de inundación en el Distrito Santa Fe. Peligro y vulnerabilidad socio-ambiental, 2010.

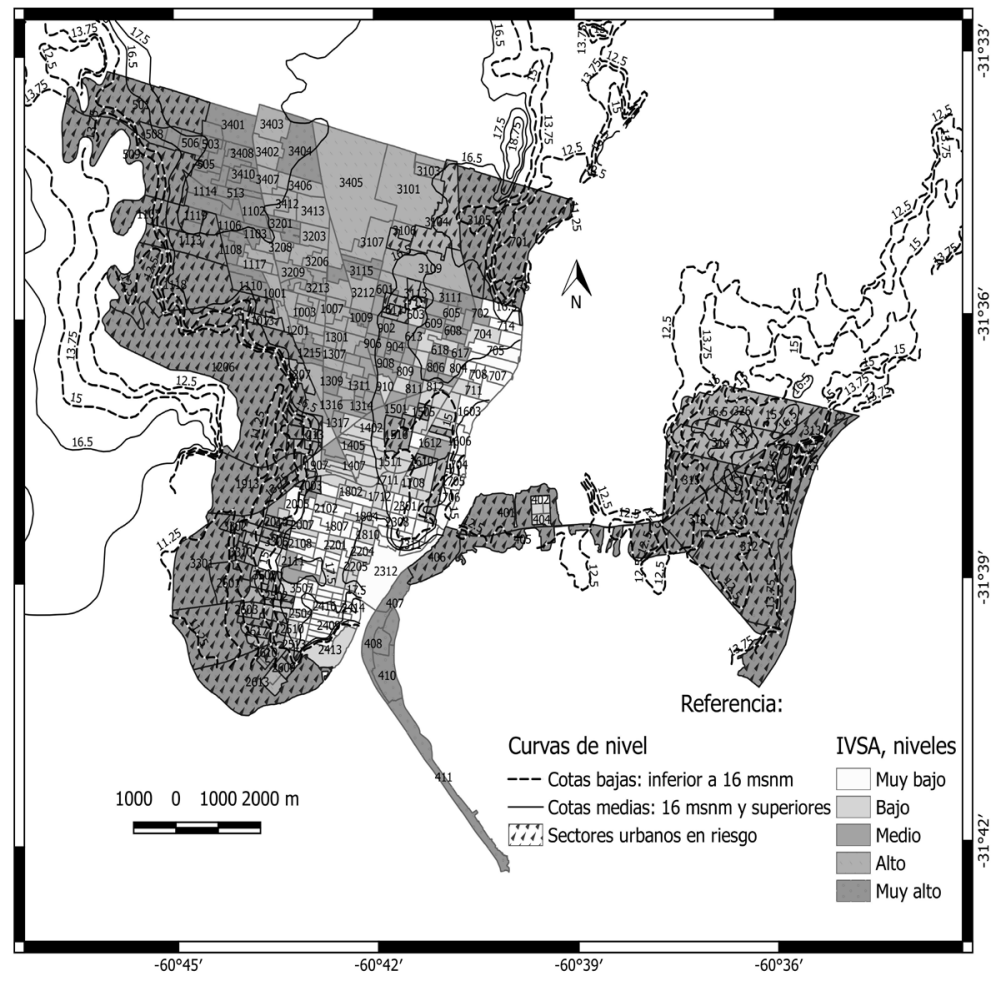

Fuente: Elaboración propia.

Según el análisis de la figura $3,79^{3}$ de los 399 radios censales tienen población con niveles medio, alto y muy alto de VSA residiendo en territorio anegable (con cotas de altura inferior a los $16 \mathrm{msnm}$ ). Allí, habitan 88.247 personas, el 22,56\% de la población del distrito Santa Fe afectado directamente a los eventos meteorológicos extremos. Por otro lado, sin considerar el tipo de peligro concreto, abriendo el abanico de posibilidades, la población del distrito Santa Fe vulnerable a cualquier fenómeno peligroso ascendería a 275.757 habitantes.

Los radios de media, alta y muy alta de vulnerabilidad socio-ambiental son 79 en total, identificados con los siguientes ID: 501, 509, 3104, 3105, 701, 1107, 1113, 1118, 3113, 602, 1111, 1206, 611, 610, 1013, 1207, 1210, 326, 1505, 313, 317, 1211, 1507, 1510, 314, 1214, 1611, 1213, 1908, 1901, 1902, 325, $1913,315,1703,1610,1909,312,2003,319,1911,401,3303,3301,2010,3302,316,3304,2011,318,405,406,2012,3305$, 3306, 3310, 3309, 2602, 2601, 3501, 3502, 3504, 3505, 3503, 2501, 2502, 2616, 2603, 2506, 2507, 2605, 2511, 2617, 2512, 2606, 2607, 2613, 2608, 2609. 
Si bien son múltiples los factores que influyen en la vulnerabilidad de las personas, un análisis posible es indagar en aquellos directamente relacionados a los niveles muy bajos y muy altos, es decir a los extremos. Justifica esta decisión la necesidad de dotar de elementos de diagnóstico para fomentar, mejorar, enriquecer, favorecer los factores que reducen la vulnerabilidad y contribuyen a la resiliencia y erradicar, reducir, reprogramar los que la elevan.

\section{Figura $N^{\circ} 5$}

Las redes de comunicación y transporte en el Distrito Santa Fe como factores de resiliencia. 2017.

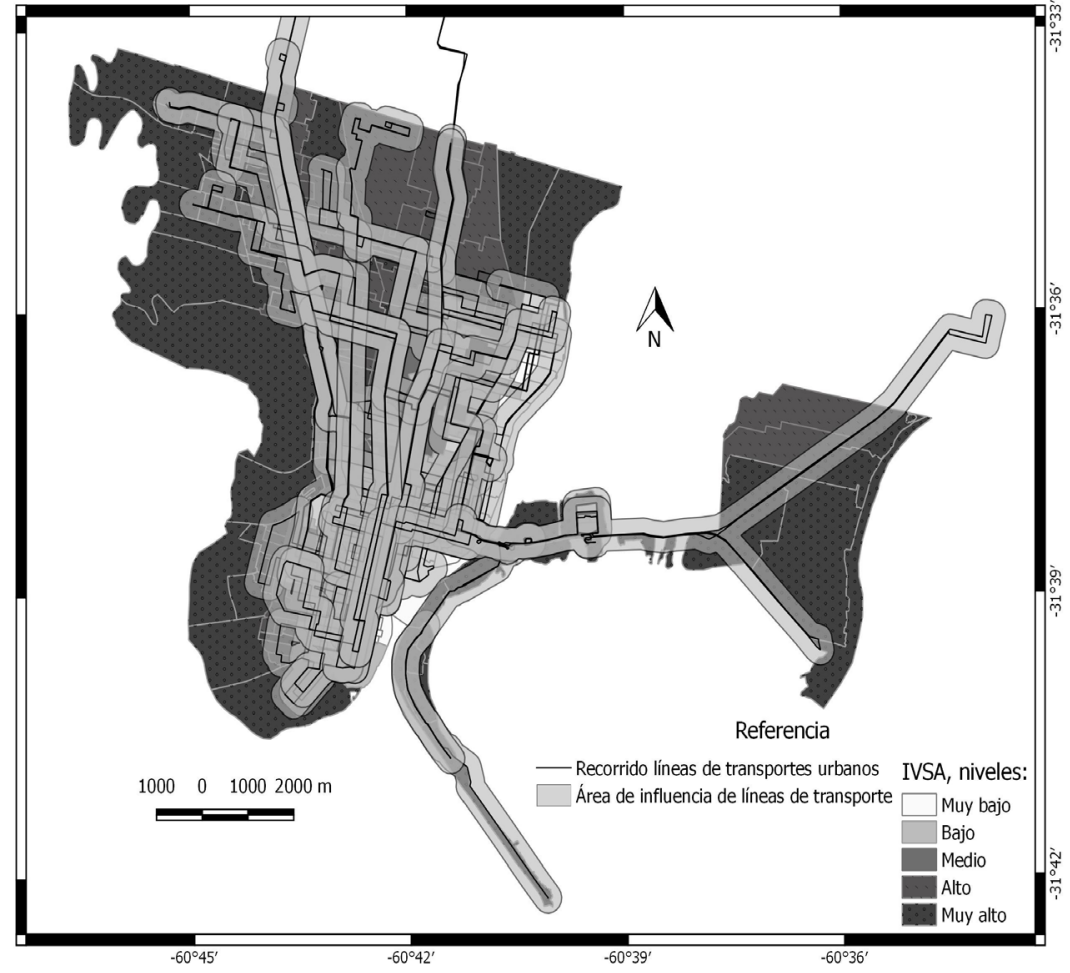

Fuente: Elaboración propia en base a datos de Gobierno de la Municipalidad de Santa Fe, "¿Cuándo pasa?", disponible en: http://cuandopasa.efibus.com.ar/

En la Figura $N^{\circ} 5$ se cartografía el recorrido y área de influencia de todas las líneas de transporte urbano que circulan en la ciudad de Santa Fe en 2017. El área de influencia se trazó con una distancia de 300 metros respecto a la vialidad por la que transita el colectivo (distancia considerada de accesibilidad para toda persona en días de buen tiempo o de lluvia). Al momento del relevamiento (marzo 2017), estaban habilitadas 22 líneas de autobuses ${ }^{4}$, algunas complementarias de otras. Analizando el trazado del recorrido de los autobuses urbanos de la figura, se observa que está directamente relacionado a las características de las vías de comunicación: los colectivos transitan por avenidas y vialidades más importantes, en mejor estado y pavimentadas, evitando aquellas que están en malas condiciones o son de tierra. Los sectores urbanos desprovistos de 
líneas de transporte (oeste, norte y distritos ribereños del este) carecen de vialidades apropiadas: son de tierra o ripio, están en mal estado y en ocasiones ni siquiera tienen un trazado regular. El análisis espacial arroja que en los sectores urbanos con niveles de vulnerabilidad bajo o muy bajo existe una superposición y sobre-oferta de trayectos de transportes urbanos (las líneas convergen y circulan por las mismas vialidades): esto es en el micro y macrocentro santafesino, en las calles San Jerónimo, 9 de julio, Mendoza, Rivadavia, 25 de mayo, y en las avenidas que comunican con el norte: Avenida Blas Parera, Aristóbulo del Valle, General Paz. El problema que surge de esta disposición es un caos vehicular y congestionamientos de tráfico, con todos los inconvenientes asociados (ruido, contaminación, accidentes, etc.). Por otro lado, estos sectores que "gozan" del beneficio de accesibilidad, se piensan menos vulnerables ante catástrofes del tipo que se analizan.

La Figura $N^{\circ} 5$ permite claramente visualizar cuáles son los territorios de la inaccesibilidad, coincidentes con los de mayor vulnerabilidad socio-ambiental: todo el cordón oeste santafesino, al que se estima que tardarán en llegar las líneas de transporte, en primer lugar por la falta de un trazado amanzanado y de vialidades, (las calles que existen están en muy mal estado), y en segundo lugar, porque esos barrios cuentan con altos grados de inseguridad y delincuencia, por lo que tanto choferes como empresarios del transporte no pueden ingresar a prestar el servicio. El norte santafesino, área de avance del ejido urbano donde se mezclan usos de suelo urbanos con rurales, como las quintas hortícolas, también evidencia porciones de territorio con inaccesibilidad al transporte público urbano (radios 701, 3105, 3104, 3405). En semejantes condiciones se ubican las localidades de la ribera, con radios de alta y muy alta vulnerabilidad $(312,325,317,318)$ los cuales poseen gran parte de su territorio sin disponibilidad de transportes o con una sola o dos líneas que lo prestan, la 13 y la Boca para Alto Verde y la 2 y la 9 para el Pozo y solo la 2 para Colastiné.

La accesibilidad que ofrecen las trayectorias o recorridos de los transportes públicos urbanos es una de las tantas externalidades positivas que contribuyen a disminuir la vulnerabilidad de la población, dado que en momentos de tormentas, inundaciones, granizadas y demás manifestaciones hidrometeorológicas (u otro tipo de catástrofes que puedan darse) el poder movilizarse hacia centros de salud, de educación, centros de inundados o bien al trabajo, resulta crucial y hasta imprescindible para la sobrevivencia. Por ello, se considera que toda política pública, proyecto o programa (público-privado) que aliente, planifique u ordene los trazados del transporte, las líneas de autobuses, el surgimiento de nuevos modos de transporte público (trenes urbanos), la apertura y mejora de las vialidades, cumple un rol fundamental en el avance de la resiliencia para el tratamiento del riesgo. Esto es así, porque se estaría dotando a la población de una herramienta fundamental para afrontar los desastres, que desde momentos históricos se vienen desarrollando en Santa Fe, y que con el correr de los tiempos, en lugar de disminuir, se agravan. Esta herramienta son nuevos y mejores servicios.

\section{Conclusiones}

La construcción teórica aquí presentada toma aportes tanto del enfoque ambiental o ecológico, como de los estudios latinoamericanos. Los sistemas de riesgo, se caracterizan por ser inestables, altamente desequilibrados, propensos a crisis que pueden provocar daños. El enfoque sistémico resulta de gran utilidad para estudiar los elementos del sistema, sus relaciones, los procesos y las fuerzas que los motorizan. Así llegamos a distinguir desastre de riesgo, vulnerabilidad 
de resiliencia, adoptando otras nociones con gran capacidad explicativa como adaptabilidad, transformabilidad e inherencia. De la perspectiva de los estudios latinoamericanos se adopta la premisa de que la vulnerabilidad y los desastres, como construcciones sociales, guardan una estrecha relación con el subdesarrollo, con procesos económicos y sociales (globales, regionales y locales) que crean condiciones de vida humana de pobreza y marginalidad, que con el paso del tiempo se acentúan.

La vulnerabilidad y la resiliencia son factores que, sumados al peligro, constituyen el riesgo de desastre. La vulnerabilidad, como elemento negativo de la ecuación del riesgo, útil para el diagnóstico de las carencias y debilidades de la comunidad, se entiende como incapacidad de la población de resistir, adaptarse y recuperarse frente a un evento que implique un cambio en la vida cotidiana. La resiliencia, elemento positivo de la misma ecuación, se presenta como una habilidad que construye la comunidad a partir de la experiencia, principalmente.

Por ello, la resiliencia es mucho más que la cara opuesta de la vulnerabilidad; en ella radica la posibilidad de desarrollo, de generar una comunidad mejor, con una calidad de vida más elevada. La resiliencia en el amplio sentido del término guarda en su interior la posibilidad de un equilibrio más justo y sustentable. Vulnerabilidad y resiliencia emergen como los elementos centrales en la teoría del riesgo.

La vulnerabilidad se trata de un fenómeno multidimensional. De la construcción del IVSA fue posible identificar qué variables (públicas o privadas) tienen mayor incidencia en el indicador sintético (destacándose la elevada presencia de población pasiva, la carencia de servicios como gas de red, desagües cloacales o equipamiento para el hogar).

La cartografía de la vulnerabilidad socio-ambiental en Santa Fe muestra patrones de distribución de los niveles más vulnerables compatibles con un cordón continuo al oeste, ocupando el sitio del valle de inundación del río Salado. Son terrenos inundables, no urbanizables que fueron, hace 5 décadas ocupados irregularmente por la población de menores recursos económicos, se trata de las villas miserias santafesinas. Al norte y al este, estos niveles se disponen de manera insular o celular, en coincidencia con los aportes de geógrafos alemanes y latinoamericanos dedicados al estudio de la estructura de las ciudades. Etán directamente relacionado a la carencia de servicios urbanos, entre ellos, el transporte de pasajeros.

Es significativa la cantidad de población vulnerable que se localiza en territorio de alto riesgo hidrometeorológico: 88.247 santafesino en 2010 , el 22,56\% de los habitantes de la ciudad viven en riesgo permanente ante los efectos de las inundaciones; y 275.757 santafesinos en 2010, el 70,48 $\%$, son vulnerables a cualquier tipo de evento peligroso (crisis económica, ambiental, social, etc.) por sus condiciones socio-ambientales (son quienes habitan en radios censales de niveles medios, altos y muy altos de VSA).

El rol del transporte en la configuración del mapa de vulnerabilidad socio-ambiental es crucial; la evidencia que arroja este estudio muestra una coincidencia entre los niveles bajos y muy bajos de VSA allí donde se superponen las áreas de accesibilidad a las diferentes líneas de transportes urbano de pasajeros; por otro lado, en los vastos sectores desprovistos de esta infraestructura, se ubica la población más vulnerable. El transporte, al igual que otros servicios urbanos, como el 
agua, desagües y gas de red, considerados esenciales, o los asistenciales (educación, salud, seguridad, no tomados en cuenta para este trabajo), en la medida que no están disponibles para la población, son inaccesibles, constituyen dimensiones sumamente relevantes, componentes de la vulnerabilidad. Los mismos, al erigirse como elementos a planificar y gestionar intencionalmente por la comunidad como herramienta para la ordenación territorial y la reducción del riesgo, se transforman en instrumentos para la resiliencia, porque el acceso a servicios de calidad permite resistir y adaptarse, con una respuesta más rápida y eficiente frente a un evento catastrófico. La disponibilidad de estos servicios posibilitará tanto la evacuación, la asistencia sanitaria inmediata, el suministro de alimentos, agua, remedios, seguridad, información, puesta en marcha de protocolos y otras medidas de organización para desastres, como el retornar a la vida cotidiana, poder volver al trabajo y a la escuela.

De este modo, dotando y mejorando los servicios en Santa Fe, se puede incidir en la adaptabilidad y transformabilidad del sistema, ya que la gestión intencional y estratégica contribuirá a un sistema urbano más resiliente, menos vulnerable y más sustentable. Las dos cualidades de la resiliencia se presentan para el caso de estos servicios: la inherencia, o perdurabilidad de las funciones del sistema durante la crisis. Respecto a este punto, considerando que los episodios de inundaciones han provocado el corte de las vías de comunicación por anegamientos, se ve la necesidad de avanzar en la planificación de otros modos de transportes menos susceptibles a estas catástrofes, como el ferroviario. La otra cualidad es la adaptabilidad, que representa la flexibilidad para responder ante el desastre. Para ello es preciso fortalecer las instituciones, organizaciones y mecanismos de participación ciudadana.

\section{Índice de siglas}

CNPHyV: Censo Nacional de Población, Hogares y Viviendas

INDEC: Instituto Nacional de Estadística y Censo

IPEC: Instituto Provincial de Estadística y Censo

IVSA: Índice de Vulnerabilidad Socio-ambiental

VSA: Vulnerabilidad Socio-ambiental.

\section{Referencias bibliográficas}

ALBINO, A. Gobernar es poblar. Criterios antropológicos y éticos para una correcta educación sexual. Tercera edición. Buenos Aires: Ed Logos, 2010.

ARRILLAGA, H.; GRAND, M. L.; BUSSO, G. Vulnerabilidad, riesgo y desastres. Sus relaciones de causalidad con la exclusión social en el territorio urbano santafesino. En: HERZER, H. ARRILLAGA, H. (Comp.). La construcción social del riesgo y el desastre en el aglomerado Santa Fe. Santa Fe: Universidad Nacional del Litoral, 2009, p. 59- 104.

BÄHR, J; MERTINS, G. Idealschema der social-räumlichen Differenzierung lateinamerikanischer. Grosstädte: Geogrphische Zietschrift, 1981, № 69, p. 1-33. 
BARRENECHEA, J.; GENTILE, E.; GONZÁLEZ, S.; NATENZON, C. Una propuesta metodológica para el estudio de la vulnerabilidad social en el marco de la teoría social del riesgo. IV Jornadas de Sociología, Buenos Aires: Universidad de Buenos Aires, 2000.

BLAIKIE, P; CANNON, T; DAVIES, I; WISNER, B. Vulnerabilidad. El entorno social, político y económico de los desastres. Primera edición. Bogotá: La Red. Red de Estudios Sociales en Prevención de Desastres en América Latina, 1996.

BOOTH, C. Poverty maps of London. London School of Economics and Political Science. On line archive, Disponible en: http://booth.Ise.ac.uk/static/a/4.html\#ii, 1903.

BORDOF, A. Cómo modelar el desarrollo y la dinámica de la ciudad latinoamericana. EURE, 2003, $N^{\circ} 29(86)$, p. 37-49.

BUZAI, G. Mapas sociales urbanos. Buenos Aires: Lugar, 2014.

CON, M. Índice de vulnerabilidad social. Documento metodológico. Informes temáticos de la Dirección de investigación y estadística, Buenos Aires: Ministerio de Educación del Gobierno de la Ciudad de Buenos Aires, 2009.

CUNY, F. Disasters and Development. Oxford: Oxford University Press, 1983.

CUTTER, S.; SOLEKI, W. D. The National pattern of airborne toxic reléase. The professional Geographer, 1989, N41, p. 149-161.

CUTTER, S. L. Vulnerability to environmental hazards. Progress in Human Geography, 1996, N 20(4), p. 529-539.

CUTTER, S.; MITCHELL, J.: SCOTT, M. Revealing the vulnerability of people and places: a case study o Georgetown County, South Carolina. Annals of the Association of American Geographers, 2000, N $90(4)$, p. 713-737.

CUTTER, S. Hazard vulnerability and environmental justice. New York: Earthscan, 2006.

CUTTER, S. L.; BARNES, L.; BERRY, M.; BURTON, C.; EVANS, E.; TATE, E.; WEBB, J. A place-based model for understanding community resilience to natural disasters. Global Environmental Change, $2008, N^{\circ} 18$, p. 598-606.

FOSCHIATTI, A. M. Aportes conceptuales y empíricos de la vulnerabilidad global. Resistencia: Ed. Universitaria de la Universidad Nacional del Nordeste, 2009.

FORD, L. A new and improved model of Latin American city structure. Geographical Review, 1996, $\mathrm{N}^{\circ} 89$ (3), p. 437-440.

GRIFFIN, E; FORD, L. A model of Latin American city structure. Geographical Review, 1980, № 70 (4), p. 397-422. 
HOLLING, C. S. Resilience and stability of ecological systems. Annual Review of Ecological Systems, $1973, \mathrm{~N}^{\circ} 4$, p. 1-23.

IBARRARÁN, M. E.; REYES, M.; ALTAMIRANO, A. Medición de la vulnerabilidad ante desastres hidrometeorológicos extremos. Repositorio institucional, Puebla: Universidad Iberoamericana de Puebla, 2014.

INDEC, Instituto Nacional del Estadística y Censo, Argentina. (2010). Censo Nacional de Población, Hogares y Viviendas 2010 (Datos definitivos).

JANOSCHKA, M. Un modelo de la ciudad latinoamericana. Coloquio internacional "La ciudad en cuestión". Abstracts y programas. Cátedra Walter Gropius -DAAD- FADU-UBA, Bs. As, 2002.

LAVELL, A. Antecedentes, formación y contribución al desarrollo de conceptos, estudios y la práctica en el tema de los riesgos y desastres en América Latina: 1980-2004. San José: Red de Estudios Sociales en Prevención de Desastres en América Latina, 2004.

MASKREY, A. (Comp.) Los desastres no son naturales. La red: Red de estudios sociales en prevención de desastres en América Latina, 1993.

MERTINS, G. La diferenciación socioespacial y funcional de las ciudades intermedias latinoamericanas: ejemplos del noroeste argentino. Revista Interamericana de Planificación, 1995, № 112, p. 55-68.

MINUJíN, A. ¿La gran exclusión? Vulnerabilidad y exclusión en América Latina. En: FILMUS, D (comp.). Los noventa. Política, sociedad y cultura en América Latina. Buenos Aires: FLACSO/EUDEBA, 1999, p. 53-77.

MORENO JIMÉNEZ, A.; ESCOLANO UTRILLA, S. Los servicios y el territorio. Madrid: Síntesis, 1992.

NATENZON, C. Vulnerabilidad social, catástrofes y cambio climático. Comentarios temáticos, teóricos y metodológicos para América Latina. II Conferencia Regional sobre mudanzas globais: América do Sul. San Pablo: Universidad de San Pablo, 2005.

PÉREZ-FOGUET, A. (Ed). Asentamientos humanos e infraestructura de servicios urbanos. Tecnología para el desarrollo humano y acceso a los servicios básicos. Barcelona: Asociació Catalana d'Enginyeria Sense Fronteras, 2005.

PNUD: Programa de Naciones Unidas para el Desarrollo. Informe sobre Desarrollo Humano 2014. Sostener el Progreso Humano: reducir vulnerabilidades y construir resiliencia. New York, 2014.

TUMINI, I. Acercamiento teórico para la integración de los conceptos de resiliencia en los indicadores de sostenibilidad urbana. Universidad de Chile, Revista de Urbanismo, 2016, N 34, p. 4-20.

VARGAS, J. E. Políticas públicas para la reducción de la vulnerabilidad frente a los desastres naturales y socio-naturales, Serie medio ambiente No 50, Santiago de Chile: CEPAL, 2002. 
WALKER, B.; HOLLING, C. S.; CARPENTER, S. R.; KINZIG, A. Resilience, adaptability and transformability in social-ecological systems. Ecology and society, 2004, N 9 (2), p. 1-9.

WILCHES CHAUX, G. La vulnerabilidad global. En: MASKREY, A. (Compilador). Los desastres no son naturales. Red de estudios sociales en prevención de desastres en América Latina, 1993.

\section{Otras fuentes}

Gobierno de la Municipalidad de Santa Fe, "¿Cuándo pasa?", disponible en: http://cuandopasa. efibus.com.ar/

Instituto Geográfico Nacional. "SIG 250": Sistema de Referencia WGS 84 y el Marco de Referencia POSGAR 07. (Código EPSG: 4326). 
